\title{
PENGARUH PEMBERIAN BERBAGAI JENIS ABU MINERAL TERHADAP PERTUMBUHAN BEBERAPA VARIETAS PADI (Oryza sativa L.) DAN SERAPAN Si
}

\author{
THE EFFECT OF GIVING VARIOUS TYPES OF MINERAL ASH TO THE \\ GROWTH OF SEVERAL RICE VARIETES AND SILLICATE UPTAKE
}

\author{
Islamul Homsi“, R. Sri Tejo Wulan, I Ketut Ngawit \\ Program Studi Agroekoteknologi, Fakultas Pertanian Universitas Mataram, Mataram, Indonesia \\ *Email Penulis Korespondensi: islamulhomsi@gmail.com
}

\begin{abstract}
ABSTRAK
Penelitian ini bertujuan untuk mengetahui pengaruh pemberian berbagai jenis pupuk abu mineral terhadap pertumbuhan beberapa varietas padi (Oryza sativaL.,) dan serapan silikat (Si).Percobaan ini dilaksanakan pada bulan Juni sampai bulan Juli 2018 menggunakan pot percobaan di rumah kaca Fakultas Pertanian Universitas Mataram. Rancangan yang digunakan yaitu Rancangan Acak Kelompok (RAK) Faktorial yang terdiri dari dua (2) faktor yaitu faktor abu (abu sekam padi, abu kulit kacang tanah dansampah kota) dan faktor varietas (Inpari 32 dan Ciherang), dan setiap kombinasi perlakuan diulang sebanyak tiga (3) kali. Data yang diperoleh dianalisis menggunakan Analisis of Varians (ANOVA) dan jika terdapat perbedaan antar perlakuan maka dilakukan uji lanjut dengan menggunakan uji Beda Nyata Jujur (BNJ) pada taraf nyata 5\%. Hasil penelitian menunjukkan bahwa: 1) BV tertinggi ditunjukkan oleh abu sampah kota, $\mathrm{pH}$ tertinggi ditunjukkan oleh abu sampah kota, C-Organik tertinggi ditunjukkan oleh abu sampah kota, $\mathrm{N}$ Total tertinggi ditunjukkan oleh abu sekam padi, dan $\mathrm{C}-\mathrm{N}$ rasiotertinggi ditunjukkan oleh abu sampah kota. 2) perlakuan abu (abu sekam padi, kuit kacang tanah, dan abu sampah kota) (A) dan kombinasi abu (A) dan varietas (V) tidak berpengaruh nyata terhadap semua parameter yang diamati. 3) perlakuan varietas Inpari 32 (V1) berpengaruh nyata terhadap berat berangkasan basah dan berat berangkasan kering. Seain itu varietas Inpari 32 lebih responsif; dan varietas Inpari 32 ini lebih superior dibandingkan dengan varietas Ciherang. 4) perlakuan abu sampah kota (A3) dan interaksi abu sampah kota dan varietas Ciherang (A3V2) menunjukkan serapan Silika tertinggi jika dibandingkan abu yang lain.
\end{abstract}

Kata Kunci: Tanaman Padi, Tanah Entisol, Pupuk Abu Mineral

\begin{abstract}
This study aims to determine the effect of various types of mineral ash fertilizer on the growth of several rice varieties (Oryza sativaL.) And silicate uptake (Si). This experiment was conducted from June to July 2018 using an experimental pot in the greenhouse of the Faculty of Agriculture, University of Mataram. The design used was Factorial Randomized Block Design (RAK) consisting of two (2) factors namely ash factor (rice husk ash, peanut husk ash and municipal waste) and variety factors (Inpari 32 and Ciherang), and each treatment combination was repeated as much as three (3) times. The data obtained were analyzed using Analysis of Variance (ANOVA) and if there were differences between treatments then further tests were carried out using the Honest Real Difference test (BNJ) at the 5\% real level. The results of the study indicate that:1) The highest BV is indicated by municipal waste ash, the highest $\mathrm{pH}$ is indicated by municipal waste ash, the highest $\mathrm{C}$-organic is indicated by municipal waste ash, the highest total $\mathrm{N}$ is indicated by rice husk ash, and high racial $\mathrm{C}-\mathrm{N}$ is indicated by municipal waste ash.2) the treatment of ash (rice husk ash, peanut butter, and municipal waste ash) (A) and the combination of ash (A) and variety (V) did not significantly affect all observed parameters.3) the treatment of the Inpari 32 (V1) variety had a significant effect on the weight of wet and dry weight. The other varieties of Inpari 32 are more responsive; and the Inpari 32 variety is superior to the Ciherang variety.4) treatment of municipal waste ash (A3) and interaction of municipal waste ash and Ciherang variety (A3V2) show the highest absorption of silica compared to other ash.
\end{abstract}

Keywords: Rice Plant, Entisol Soil, Mineral Ash Fertilizer

Homsi, I., Wulan, R. S. T., dan Ngawit, I K. 


\section{PENDAHULUAN}

Tanaman padi (Oryza sativa L.) merupakan tanaman pangan penting yang menjadi makanan pokok lebih dari setengah penduduk dunia karena mengandung nutrisi yang diperlukan tubuh. Menurut Poedjiadi (1994), kandungan karbohidrat padi giling sebesar $78,9 \%$, protein $6,8 \%$, lemak $0,7 \%$ dan lain-lain $0,6 \%$. Indonesia sebagai negara dengan jumlah penduduk yang besar menghadapi tantangan dalam memenuhi kebutuhan pangan tersebut. Peran beras (padi) sebagai makanan pokok di Indonesia sampai saat ini sulit disubstitusikan dengan jenis makanan pokok yang lain. Bahkan ketergantungan terhadap komoditi ini masih cukup tinggi (Septiadi \& Joka, 2019). Namun permintaan padi domestik yang terus meningkat, mengharuskan pemerintah untuk mengimpor dari negara lain (Septiadi et al, 2016). Hal ini memerlukan kebijakan pemerintah untuk terus berupaya dalam meningkatkan produksi padi nasional. Salah satu strategi yang dapat dilakukan adalah melalui upaya peningkatan kualitas kesuburan tanah/lahan serta tindakan perbaikan dalam pemupukan dengan menggunakan pupuk altrnatif (Diantoro et all. 2009).

Praktek pemupukan sudah lama dilakukan oleh petani namun pelaksanaannya yang kurang bijak telah menyebabkan terjadinya berbagai kerusakan tanah seperti : (1) rusaknya keseimbangan unsur hara didalam tanah, (2) berkurangnya bahan organik tanah (BOT), (3) berkurangnya keanekaragaman organisme hayati tanah, (4) rusaknya struktur tanah, dan (5) kerusakan sifat fisik, kimia dan biologi tanah lainnya. Untuk mengatasi permasalahan tersebut maka diperlukan adanya penggunaan bahan pupuk alternatif dan perbaikan dalam cara pemupukannya (Meyovy, 2011).

Salah satu sumber daya yang dapat dijadikan sebagai bahan pupuk alternatif adalah abu hasil pembakaran biomassa seperti : (1) limbah abu pembakaran batu bata, (2) abu energi pembuatan tahu tempe, (3) abu kerajinan industri genteng, (4) abu pembakaran cangkang kelapa sawit, dan (5) abu sisa pembakaran sampah kota. Berbagai limbah abu tersebut tersedia dalam jumlah banyak dan belum dimanfaatkan secara optimal sehingga terbuka peluang yang besar untuk memanfaatkannya sebagai sumber bahan pupuk alternatif. Dari berbagai limbah abu tersebut: abu sekam padi, abu kulit kacang tanah, dan abu sampah kota menjadi perhatian khusus dalam penelitian ini, mengingat ketersediaannya yang cukup banyak di pulau Lombok (Sudaryono et al. 2011).

Dengan berbagai kandungan unsur hara yang terdapat di dalamnya, penambahan bahan abu ke dalam tanah sebagai pupuk diyakini akan dapat meningkatkan sifat kimia tanah seperti: (1) meningkatnya kandungan berbagai unsur hara didalam tanah, (2)meningkatnya kemampuan tanah dalampengikatan logam, (3) meningkatkan kemampuan kapasitas tukar kation (KTK) tanah. Sedangkan ditinjau dari aspek fisika tanah penambahan abu kedalam tanah dapat: (1) meningkatkan atau mengatur kelembaban tanah, (2) meningkatkan infiltrasi tanah,menstabilkan temperatur tanah, (3) memperbaiki struktur tanah. Selain itu, pemberian abu juga dapat meningkatkan kualitas sifat biologi tanah seperti: (1) meningkatkan kondisi lingkungan hidupdidalam tanah, (2) meningkatkan sumber makanan dan energi bagi mikroorgansme tanah, dan (3) meningkatkan jumlah dan jenis mikrobia tanah.

Kajian penambahan pupuk abu tersebut akan dilaksanakan menggunakan tanah sawah berordo entisol. Tanah entisol banyak terdapat dipulau Lombok dan menjadi salah satu sentra produksi tanaman padi diNTB. Tanah sawah yang berkembang dari ordo entisol umumnya memiliki: (1) kesuburan tanah dan kandungan bahan organik yang rendah,(2) daya menahan airnya rendah, dan (3) struktur remah sampai berbutir dan sangat sarang. Sehingga memiliki potensi jika dikelola dengan baik dalam budidaya 
padi (Jamilah,2003). Penambahan abu ke dalam tanah entisol diharapkan akan mampu memperbaiki kesuburan tanah entisol dan pada akhirnya akan mendukung produksi tanaman padi yang di tanam pada lahan sawah tersebut.

Berdasarkan uraian tersebut diatas, maka dipandang perlu untuk melakukan kajian berjudul Pengaruh Pemberian Berbagai Jenis Pupuk Abu Mineral Terhadap Pertumbuhan Beberapa Varietas Padi (Oryza Sativa L.,) dan Serapan Silikat (Si). Penelitian ini bertujuan untuk mengetahui karakteristik dari abu (abu sekam padi, kulit kacang tanah, dan abu sampah kota) seperti, BV, pH, C-Organik, $\mathrm{N}$ Total, dan $\mathrm{C} / \mathrm{N}$ rasio dan pengaruh pemberian berbagai jenis abu (abu sekam padi, abu kulit kacang tanah, dan abu sampah kota) terhadap pertumbuhan, hasil, dan serapan Si pada jaringan tanaman padi. Hasil penelitian ini diharapkan berguna dalam menyediakan informasi bagi masyarakat dan dapat dijadikan sebagai acuan bagi mahasiswa yang akan melakukan penelitian mengenai pemanfaatan berbagai jenis limbah abu hasil pembakaran biomassa seperti (abu sekam padi, abu kulit kacang tanah, dan abu sampah kota) sebagai bahan pupuk untuk mendukung pertumbuhan tanaman padi.

\section{METODE PENELITIAN}

\section{Waktu dan Tempat Penelitian}

Penelitian ini telah dilaksanakan pada bulan Juni-Juli 2018 di rumahkaca Fakultas Pertanian, Universitas Mataram.

\section{Alat dan Bahan Penelitian \\ Alat Penelitian}

Alat yang digunakan dalam penelitian ini adalah: cangkul, sekop, ayakan, ember plastik, gembor, timbangan, meteran, alat tulis menulis, dan alat-alat yang digunakan dalam analisis di laboratorium.

\section{Bahan Penelitian}

Bahan yang digunakan dalam penelitian ini adalah: abu sekam padi, abu kulit kacang tanah, abu sampah kota, tanah entisol, benih tanaman padi (Inpari 32 dan Ciherang), dan bahan-bahan yan digunakan dalam analisis di laboratorium.

BLOK I

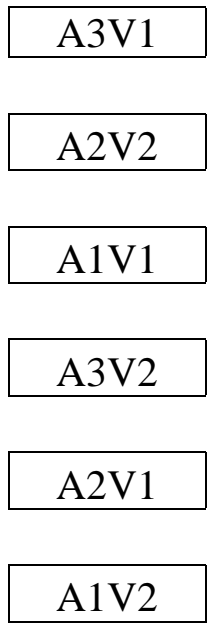

\section{BLOK II}

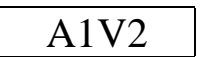

\section{A3V1}

$\mathrm{A} 2 \mathrm{~V} 2$

\section{A1V1}

$\mathrm{A} 3 \mathrm{~V} 2$

A2V1
BLOK III

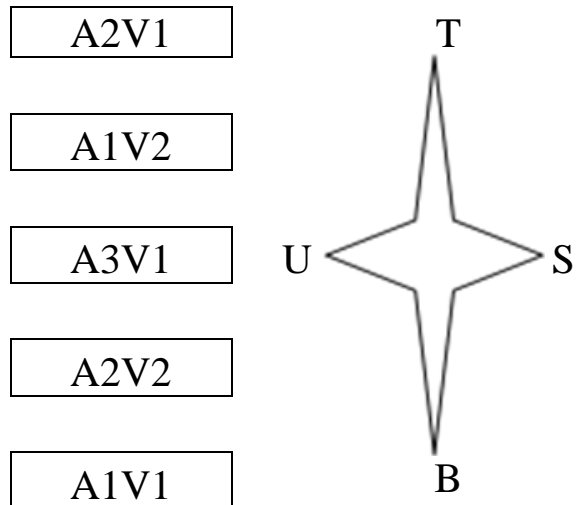

A3V2

Gambar 1. Denah percobaan 


\section{Rancangan Penelitian}

Rancangan percobaan yang digunakan dalam penelitian ini adalahRancangan Acak Kelompok (RAK) faktorial, terdiri dari 2 faktor perlakuan yaitu tiga jenis abu (abu sekam padi,sampah kota, dan abu ampas kulit kacang tana) dan dua (2) jenis varietas varietas Inpari 32 dan ciherang. Faktor perlakuan abu (A) dapat dilihat pada Gambar 1.

\section{Pelaksanaan Penelitian}

Penelitian ini mencakup beberapa kegiatan mulai dari tahap persiapan (persiapan tanah, persiapan abu, persiapan media tanam, persiapan benih padi), hingga penanaman, pemeliharaan, dan pemanenan.

\section{Persiapan Tanah}

Tanah yang digunakan dalam penelitian ini adalah tanah sawah Entisol yang berkesuburan rendah yang dicirikan oleh warna tanah yang terang, tekstur tanah pasiran, dan struktur tanah lepas. tanam dan sampel tanah lolos mata ayak $2 \mathrm{~mm}$ untuk tujuan analisis.

\section{Persiapan Abu}

Pupuk abu yang digunakan dalam penelitian ini meliputi: abu sekam padi, abu kulit kacang tanah, dan abu sampah kota yang merupakan hasil dari pembakaran biomassa.

\section{Persiapan Media Tanam dan Persemaian}

Sebanyak $10 \mathrm{~kg}$ contoh tanah ditambah abu sebanyak 0,5 kg sesuai dengan masingmasing perlakuan. Kedua bahan tersebut diaduk dan dicampur secara merata untuk mendapatkan campuran media tanam yang homogen. Masing-masing campuran media tanam dimasukkan kedalam pot-pot percobaan yang telah dipersiapkan sesuai dengan perlakuan. Media tanam yang telah dipersiapkan tersebut kemudian diinkubasikan selama 21 hari dengan cara menggenangi tanah tersebut dengan air $(2-3 \mathrm{~cm})$ dengan maksud untuk menjamin telah tercapainya keseimbangan sifat fisika, kimia dan biologi tanah pada media tanam tersebut.

\section{Persiapan Benih Padi}

Benih padi yang digunakan dalam penelitian ini adalah benih padi varietasciherang dan Inpari 32. Kedua (2) varietas padi tersebut diperoleh dari petani yang menanam di tanah sawah benih padi yang berlokasi di Narmada.

\section{Penanaman}

Sebanyak 2-3 bibit padi ditanam pada pot-pot percobaan yang telah disiapkan sesuai dengan perlakuan. Penanaman padi dilakukan pada kedalaman 3-4 $\mathrm{cm}$ dari permukaan tanah. Penanaman dilakukan dalam kondisi lengas tanah macak-macak.

\section{Penyulaman}

Penyulaman dilakukan apabila benih padi tidak tumbuh, mati, rusak, dan/atau tumbuh tidak normal. Penyulaman akan dilakukan pada saat padi berumur 7 hari setelah tanam ( HST), dengan cara menggantinya dengan bibit yang sehat dari persemaian yang sama. 


\section{Pemeliharaan}

1. Penyiraman

Penyiraman dilakukan dengan cara menjaga ketinggian genangan air 2-3 cm dari permukaan tanah.

2. Penyiangan

Penyiangan dilakukan dengan cara mencabut gulma secara manual pada usia gulma sedini mungkin.

3. Pemupukan

Pemupukanpada tanaman padi dilakukan sebanyak dua kali selama masa percobaan. Pemupukan pertama dilakukan pada saat tanaman padi berumur 40 hari setelah semai (HSS). Pemupukan pertama ini dilakukan dengan cara menambahkan 1/2 dari 1/2 dosis pupuk phonska yang direkomendasikan untuk tanaman padi (250/Ha). Pemupukan kedua dilakukan pada saat tanaman padi mencapai fase bunting, yang dilakukan dengan cara menambahkan $1 / 2$ dari pupuk yang tersisa.

4. Pengendalian Hama dan Penyakit

Untuk mengatasi serangan hama dan penyakit pada tanaman padi dilakukan menggunakan ekstrak insektisida alami daun nimba (dalam kondisi serangan ringan).

\section{Panen}

Pemanenan dilakukan setelah tanaman padi mencapai pertumbuhan vegetatif maksimum, yang ditandai oleh telah keluarnya malai pada $85 \%$ populasi tanaman.

\section{Parameter Pengamatan}

Parameter yang diamati dalam penelitian ini adalah tinggi tanaman, jumlah anakan, umur berbunga, berat berangkasan basah, berat berangkasan kering, dan serapan Sipada jaringan tanaman padi.

\section{Tinggi Tanaman (cm per minggu)}

Pengamatan tinggi tanaman dilakukan dengan cara mengukur batang utama tanaman dari atas permukaan tanah atau pangkal batang sampai dengan daun terpanjang tanaman padi. Pengukuran tinggi tanaman dilakukan sejak tanaman berumur 7, 14, 21, 28, 35, dan 42 hari setelah tanam (HST).

\section{Jumlah Tanaman/Anakan Per Pot (batang per minggu)}

Jumlah tanaman/anakan per pot. Pengamatan dilakukan setelah panen dengan cara menghitung satu persatu jumlah batang/tanaman pada masing-masing pot percobaan.

\section{Umur Berbunga (MST)}

Pengamatan dilakukan dengan cara menghitung jumlah hari setelah semai (HSS) hingga tanaman mengeluarkan malai.

\section{Berat Berangkasan Basah (g)}

Pengamatan berangkasan basah dilakukan dengan cara menimbang berangkasan basah dari tanaman padi seperti batang dan daun yang baru dipanen.

\section{Berat Berangkasan Kering (g)}

Pengamatan berat berangkasan kering dilakukan setelah kadar air pada berangkasan basah dihilangkan dengan cara dioven. 


\section{Serapan Si pada Jaringan Tanaman Padi}

Pengamatan total silikat ( $\mathrm{Si}$ ) dalam jaringan dilakukan melalui analisis total slikat (Si) dalam jaringan tanaman padi di laboratorium.

\section{Analisis Data}

Data hasil pengamatan di analisis dengan analisis keragaman pada taraf nyata $5 \%$. Hasil analisis keragaman yang menunjukan beda nyata diuji lanjut dengan menggunakan Uji Beda Nyata Jujur (BNJ) pada taraf nyata 5\%.

\section{HASIL DAN PEMBAHASAN}

Penelitian berjudul "Pengaruh Pemberian Berbagai Jenis Pupuk Abu Mineral Terhadap Pertumbuhan Beberapa Varietas Padi (Oryza Sativa L.) dan Serapan Silikat (Si)" telah dilakukan di rumah kaca Fakultas Pertanian Universitas Mataram menggunakan percobaan pot. Hasil yang diperoleh disajikan dalam pokok-pokok bahasan sebagai berikut: (1) Karakteristik awal tanah sebelum percobaan, (2) Karakteristik limbah abu, (3) Pertumbuhan tanaman padi, dan (4) Serapan Silikat (Si) pada jaringan padi.

\section{Karakteristik Tanah Sebelum Percobaan}

Tanah yang digunakan adalah tanah ordo Entisol yang diambil dari lahan sawah milik Amak Husni di Desa Tanak Beak, Kecamatan Narmada, Kabupaten Lombok Barat, NTB. Sebelum percobaan dilakukan analisis tanah awal (Berat Volume, pH, COrganik, N Total, dan C/N Rasio) untuk mengetahui kondisi kesuburan tanah yang akan digunakan. Data hasil analisis awal tersebut disajikan pada Tabel 1.

Tabel 1. Hasil Analisis Awal Tanah

\begin{tabular}{clccc}
\hline No & \multicolumn{1}{c}{ Parameter } & Satuan & Nilai & Harkat \\
\hline 1 & Berat Volume & g/cm3 & 1,19 & Normal \\
2 & Ph & & 6,05 & Agak Masam \\
3 & C-Organik & $\%$ & 1,20 & Rendah \\
4 & N Total & $\%$ & 0,13 & Rendah \\
5 & C/N Rasio & & 9,2 & Normal \\
\hline
\end{tabular}

Sumber: Data Primer diolah (2020)

\section{Berat Volume Tanah}

Hasil analisis berat volume tanah (BV) menunjukkan nilai $1,19 \mathrm{~g} / \mathrm{cm}^{3}$, yang mengindikasikan BV tanah normal(1,0 - 1,2 $\left.\mathrm{g} / \mathrm{cm}^{3}\right)$. BV tanah sangat berpengaruh terhadap aerasi dan drainase tanah, yang secara langsung maupun tidak langsung dapat mempengaruhi kemampuan pertumbuhan akar tanaman dan penyerapan air dan unsur hara.

\section{pH Tanah}

pH merupakan ukuran derajat nilai kemasaman dan kebasaan tanah. Data pada Tabel 4.1.menunjukkan bahwa tanah yang digunakan dalam penelitian ini memiliki pH 6,05. Menurut Rosmarkan dan Yuwono (2002), pH 6,05 dapat digolongkan kedalam tanah yang bersifat agak masam. Nilai $\mathrm{pH}$ tersebut termasuk kedalam kategori nilai $\mathrm{pH}$ normal untuk lahan sawah. Pendapat ini didukung oleh hasil survey Badan Penelitian 
Tanah (BPT) NTB (2011)yang menyatakan bahwa tanah-tanah sawah di NTB secara umum memiliki pH sekitar 5,6 - 6,5 (masam dan agak masam).

\section{C-Organik dan N Total Tanah}

Hasil analisis C-Organik tanah $(1,20 \%)$ dan $\mathrm{N}$ total tanah $(0,13 \%)$ menunjukkan tingkat kandungan bahan organik dan nitrogen yang rendah. Harkat nilai C-Organik rendah pada tanah yang digunakan dalam penelitian ini mungkin disebabkan oleh: (1) rendahnya kandungan bahan organik tanah (BOT), (2) penggunaan pupuk kimia secara intensif dan terus menerus, (3) pola tanam monokultur sepanjang tahun, dan/atau oleh (4) perbedaan kandungan jenis dan jumlah mineral liat didalam tanah. Perbaikan tingkat C-organik tanah hanya dapat dilakukan dengan penambahan bahan organik kedalam tanah. material abu sebagai bahan pembenah tanah sekaligus sebagai sumber bahan organik tanah.

\section{C/N RasioTanah}

$\mathrm{C} / \mathrm{N}$ rasio tanah merupakan perbandingan antara kandungan $\mathrm{C}$ dan $\mathrm{N}$ yang terdapat didalam tanah.Data pada Tabel 4.1.menunjukkan nilai $\mathrm{C} / \mathrm{N}$ rasio 9,2 yang merupakan nilai $\mathrm{C} / \mathrm{N}$ rasio tanah-tanah normal. Pendapat ini didukung oleh laporan Bachtiar (2006) yang menyatakan bahwa pada bagian atas tanah (top soil), nilai $\mathrm{C} / \mathrm{N}$ rasio berbeda-beda yaitu sekitar 8:1 sampai 15:1 dan rata-rata berkisar antara 10-12. Perbandingan karbon dan nitrogen $(\mathrm{C} / \mathrm{N})$ didalam tanah sangat penting utamanya kaitannya dengan ketersediaan unsur nitrogen bagi tanaman dan bagi mikroorganisme tanah.

\section{Karakteristik Abu}

Abu merupakan material hasil pembakaran biomassa pada suhu yang tinggi. Abu yang digunakan dalam penelitian ini terdiri dari abu sekam padi, sampah kota, dan abu kulit kacang tanah. Hasil analisis sifat fisik dan kimia material abu dalam penelitian ini disajikan pada Tabel 2 .

Tabel 2. Hasil Analisis Sifat Fisik dan Kimia Beberapa Material Abu

\begin{tabular}{llccc}
\hline No & Parameter & $\begin{array}{c}\text { Abu Sekam } \\
\text { Padi }\end{array}$ & $\begin{array}{c}\text { Abu Sampah } \\
\text { Kota }\end{array}$ & $\begin{array}{c}\text { Abu Kulit Kacang } \\
\text { Tanah }\end{array}$ \\
\hline 1 & Berat Volume & 0,44 & 0,89 & 0,31 \\
2 & pH & 8,82 & 10,24 & 8,44 \\
3 & C-Organik & 0,54 & 0,87 & 0,49 \\
4 & N Total & 0,31 & 0,10 & 0,25 \\
5 & C/N Ratio & 1,74 & 8,7 & 1,96 \\
\hline
\end{tabular}

Sumber: Data Primer diolah (2020)

\section{Berat Volume Abu}

Berat volume material abu berbeda-beda tergantung pada jenis dari masing-masing abu. Abu sampah kota memiliki nilai BV paling tinggi $\left(0,89 \mathrm{~g} / \mathrm{cm}^{3}\right)$ diikuti oleh abu sekam padi $\left(0.44 \mathrm{~g} / \mathrm{cm}^{3}\right)$ dan abu kulit kacang tanah $\left(0,31 \mathrm{~g} / \mathrm{cm}^{3}\right)$. BV abu kulit kacang tanah yang rendah diduga karena abu kulit kacang tanah ini memiliki struktur yang remah, berat yang ringan dan bentuk fisik yangporous.

\section{pH Abu}

Data pada Tabel 4.2.menunjukkan bahwa nilai $\mathrm{pH}$ abu berkisar antara 8,44-10,24. Nilai pH tertinggi terdapat pada abu sampah kota yaitu 10,24diikuti oleh abu kulit 
kacang tanah $(8,82)$, dan abu sekam padi $(8,44)$. Hasil ini mengindikasikan bahwa $\mathrm{pH}$ abu tergolong kedalam $\mathrm{pH}$ basa dan sangat basa.

\section{C-organikdan $\mathrm{N}$ total $\mathrm{Abu}$}

Kandungan $\mathrm{C}$-organik dan $\mathrm{N}$ total pada berbagai jenis abu menunjukkan angka yang berbeda-beda antar jenis abu. Abu sampah kota memiliki nilai C-organik tertinggi $(0,87 \%)$, diikuti oleh abu sekam padi $0,84 \%$, dan abu kulit kacang tanah $0,49 \%$. Kandungan C-organik dari ke-tiga (3) jenis material abu tersebut tergolong kedalam kategori rendah. Hal ini diakibatkan oleh telah terbakarnya sebagian besar C-organik pada material abu dalam proses pembakaran. Berbeda dengan pembakaran biomasa pada suhu rendah $\left(250-450{ }^{\circ} \mathrm{C}\right)$, proses pembakaran pada suhu tersebut menyisakan BO dalam jumlah yang relatif cukup tinggi dalam bentuk arang atau biochar, yang pada umumnya memiliki kandungan C-organik > 20\%.

\section{C/N rasio abu}

$\mathrm{C} / \mathrm{N}$ rasio abu merupakan perbandingan antara kandungan $\mathrm{C}$ dan $\mathrm{N}$ yang menunjukkan tingkat kecepatan mineralisasi bahan organik (Juliardi dkk., 2002). Setiap jenis abu menunjukkan nilai $\mathrm{C} / \mathrm{N}$ rasio yang berbeda-beda antar berbagai jenis abu. Nilai $\mathrm{C} / \mathrm{N}$ rasio ke-tiga abu tersebut tergolong sangat rendah, yaitu: abu sampah kota 8,7, abu kulit kacang tanah 1,96, dan abu sekam padi 1,74. Menurut Kuswadi (1993) pupuk organik (seperti pupuk kompos, pupuk kandang, pupuk bokashi, dan lainnya) dapat diaplikasikan sebagai pupuk kedalam tanah jika nilai $\mathrm{C} / \mathrm{N}$ rasionya $<30$.

\section{Hasil Analisis Ragam}

Tabel 3 menunjukkan rangkuman hasil analisis sidik ragam pengaruh pemberian berbagai jenis pupuk abu mineral dan dua varietas padi (Inpari 32 dan ciherang) terhadap parameter pengamatan. Sedangkan hasil analisis purata laju pertambahan tinggi tanaman, laju pertambahan jumlah anakan, dan umur berbunga disajikan pada Tabel 4.

Tabel 3. Rangkuman Hasil Analisis Sidik Ragam

\begin{tabular}{lccc}
\hline \multicolumn{1}{c}{ PARAMETER } & \multicolumn{3}{c}{ SUMBER KERAGAMAN } \\
& ABU (A) & VARIETAS (V) & INTERAKSI (AxV) \\
\hline Tinggi Tanaman & $\mathrm{ns}$ & $\mathrm{ns}$ & $\mathrm{ns}$ \\
Jumlah Anakan & $\mathrm{ns}$ & $\mathrm{ns}$ & $\mathrm{ns}$ \\
Umur Berbunga & $\mathrm{ns}$ & $\mathrm{ns}$ & $\mathrm{ns}$ \\
Berat Berangkasan Basah & $\mathrm{ns}$ & $\mathrm{s}$ & $\mathrm{ns}$ \\
Berat Berangkasan Kering & $\mathrm{ns}$ & $\mathrm{s}$ & $\mathrm{ns}$ \\
Serapan Silikat (Si) & $\mathrm{ns}$ & $\mathrm{ns}$ & $\mathrm{ns}$ \\
\hline Keterangan: $\mathrm{ns}=$ Non signifikan (tidak berbeda nyata) & \\
\multicolumn{5}{c}{$\mathrm{s}=$ Signifikan (berbeda nyata) } \\
Sumber: Data Primer diolah (2020) & & \\
\multicolumn{4}{l}{ Data pada Tabel 3.dan 4 menunjukkan bahwa perlakuan varietas (V) berpengaruh } \\
nyata terhadap berat berangkasan basah dan berat berangkasan kering tanaman padi, \\
sedangkan pemberian berbagai jenis abu (A) dan interaksi ke-dua perlakuan abu dan \\
varietas (AxV) tidak berpengaruh nyata terhadap semua parameter yang diamati.
\end{tabular}


Tabel 4. Purata laju pertambahan tinggi tanaman, laju pertambahan jumlah anakan, dan

\begin{tabular}{|c|c|c|}
\hline Perlakuan & $\begin{array}{c}\text { Laju Pertambahan Tinggi } \\
\text { Tanaman }\end{array}$ & $\begin{array}{l}\text { Laju Pertambahan Jumlah } \\
\text { Anakan dan Umur Berbunga }\end{array}$ \\
\hline A1 & $11,66 \mathrm{a}$ & $8,833 \mathrm{a}$ \\
\hline A2 & $10,98 \mathrm{a}$ & $10,42 \mathrm{a}$ \\
\hline A3 & $11,07 \mathrm{a}$ & $7,333 \mathrm{a}$ \\
\hline BNJ & - & - \\
\hline V1 & $11,51 \mathrm{a}$ & 8,78 a \\
\hline $\mathrm{V} 2$ & $10,97 \mathrm{a}$ & $8,944 \mathrm{a}$ \\
\hline BNJ & - & - \\
\hline A1V1 & $11,73 a$ & $8,833 a$ \\
\hline A1V2 & $11,59 \mathrm{a}$ & $8,833 \mathrm{a}$ \\
\hline $\mathrm{A} 2 \mathrm{~V} 1$ & $11,43 a$ & $8,833 \mathrm{a}$ \\
\hline $\mathrm{A} 2 \mathrm{~V} 2$ & $10,54 \mathrm{a}$ & $12,00 \mathrm{a}$ \\
\hline A3V1 & $11,38 \mathrm{a}$ & $8,67 \mathrm{a}$ \\
\hline $\mathrm{A} 3 \mathrm{~V} 2$ & $10,77 \mathrm{a}$ & $6,00 \mathrm{a}$ \\
\hline
\end{tabular}

\begin{tabular}{lc}
\hline BNJ & - \\
\hline Keterangan: & Angka-angka yang diikuti dengan huruf yang sama pada kolom yang sama menunjukkan
\end{tabular}
tidak berbeda nyata pada uji lanjut BNJ dengan taraf nyata $5 \%$.

Sumber: Data Primer diolah (2020)

\section{Berat Berangkasan Basah dan Berat Berangkasan Kering Tanaman Padi}

Berat berangkasan basah adalahberat biomassa segar dari tanaman yang merupakan hasil akumulasi fotosintat dari proses fotosintesis. Sedangkan berat berangkasan kering adalah berat kering tanaman setelahkadarairpada berat berangkasan basahdihilangkan melalui proses pengovenan.Berat berangkasan basah dan kering sangat ditentukan olehkemampuan dari tanaman dalam menyerap air dan hara dari dalam tanah serta olehhasil fotosintesis dari tanaman itu sendiri. Menurut Lakitan (2004) produksi berangkasan basah dan kering tanaman sangat ditentukan oleh: (1) lamanya proses penyinaran matahari, (2) jumlahunsur hara yang diserap oleh Tanaman, dan (3) penyerapan karbondioksida dan air oleh tanaman. Data hasil pengukuran berat berangkasan basah dan kering tanaman padi secara lengkap disajikan pada Tabel 5 .

Data pada Tabel 4.5.menunjukkan bahwa perlakuan varietas (V) berpengaruh nyata terhadap parameter berat berangkasan basah dan berangkasan kering tanaman padi, namun tidak berpengaruh nyata pada perlakuan interaksi antara abu $(\mathrm{AxV})$ dengan varietas.Hal ini menunjukkan bahwaV1 (varietas Inpari 32) dan V2 (varietas Ciherang) memberikan respon yang berbeda terhadap tindakan pemupukan yang diberikan. Varietas Inpari 32 memberikan hasil sebesar 132,8 g/pot berangkasan basah dan berat berangkasan kering sebesar 30,81 g/pot sedangkan varietas Ciherang hanya menghasilkan berat berangkasan basah dan berat berangkasan kering masing-masing sebesar 109,1 g/pot dan 25,18 g/pot. Hasil ini konsisten dengan potensi produksi sebagaimana tertera pada label kemasan potensi produksi pada ke-dua varietas tersebut. Varietas Inpari 32 memiliki potensi produksi sebesar 9-10 ton/ha sedangkan Ciherang 8,42 ton/ha (BPTP, 2015). 
Tabel 5. Purata Parameter Berat Berangkasan Basah (g/pot) dan Berat Berangkasan Kering Tanaman (g/pot)

\begin{tabular}{lll}
\hline Perlakuan & Berat Berangkasan Basah & Berat Berangkasan Kering \\
\hline A1 & $130,1 \mathrm{a}$ & $30,08 \mathrm{a}$ \\
A2 & $125,7 \mathrm{a}$ & $28,98 \mathrm{a}$ \\
A3 & $207,0 \mathrm{a}$ & $25,00 \mathrm{a}$ \\
\hline BNJ & - & - \\
\hline V1 & $132,8 \mathrm{a}$ & $30,81 \mathrm{a}$ \\
V2 & $109,1 \mathrm{~b}$ & $25,18 \mathrm{~b}$ \\
\hline BNJ & $\mathbf{2 4 , 8 4}$ & $\mathbf{5 , 2 4}$ \\
\hline A1V1 & $136,5 \mathrm{a}$ & $31,83 \mathrm{a}$ \\
A1V2 & $123,7 \mathrm{a}$ & $28,33 \mathrm{a}$ \\
A2V1 & $132,7 \mathrm{a}$ & $30,93 \mathrm{a}$ \\
A2V2 & $118,97 \mathrm{a}$ & $26,88 \mathrm{a}$ \\
A3V1 & $129,3 \mathrm{a}$ & $29,67 \mathrm{a}$ \\
A3V2 & $84,67 \mathrm{a}$ & $20,33 \mathrm{a}$ \\
\hline
\end{tabular}

BNJ

Keterangan: Angka-angka yang diikuti dengan huruf yang sama pada kolom yang sama menunjukkan tidak berbeda nyata pada uji lanjut BNJ dengan taraf nyata $5 \%$.

Sumber: Data Primer diolah (2020)

\section{Serapan Silikat (Si) Pada Jaringan Tanaman}

Silikat merupakan salah satu unsur hara fungsional yang sangat penting bagi tanaman padi, tebu, jagung dan beberapa tanaman lain yang bersifat akumulator Si. Meskipun tidak tergolong kedalam 16 unsur esensial, Si diketahui sebagai unsur hara yang bermanfaat (beneficialelement).Silikat ( $\mathrm{Si}$ ) banyak terdapat didalam kerak bumi dan merupakan unsur kedua terbesar di dalam tanahsetelah unsur oksigen $\left(\mathrm{O}_{2}\right)$ (Yukamgo, 2007). Silikat mempunyai peranan penting dalam meningkatkan:(1) laju fotosintesis, (2) efisiensi penggunaan air, (3) ketahanan terhadap serangan hama dan penyakit, (4) daya simpan produk hortikultura, dan (5) meningkatkan bobot dan berangkasan biji. Sedangkan kekurangan Si pada tanaman padi akan berdampak pada menurunnya: (1) laju fotosintesis, (2) efisiensi penggunaan air, (3) ketahanan tanamanterhadap penyakit, (4) kualitas produk hortikultura, dan (5) berat brangkasan tanaman (Priyono, 2014).

Data pada Tabel 6 menunjukkan bahwa perlakuan berbagai jenis abu (A) dan varietas $(\mathrm{V})$ serta interaksi keduanya $(\mathrm{AxV})$ tidak berpengaruh nyata terhadap serapan silikat pada jaringan tanaman padi.Hal ini menunjukkan bahwa (dalam penelitian ini) unsur Si tidak beperan penting terhadap pertumbuhan tanaman tetapi lebih berperan dalam melindungi tanaman terhadap keadaan yang kurang menguntungkan dari faktor lingkungan.Hasil tersebut sesuai dengan laporanYukamgo dan Yuwono (2007), yang menyatakan bahwa unsur Si tidak berperan dalam meningkatkan laju pertambahan tinggi tanaman, jumlah anakan, dan umur berbunga melainkan berperan penting dalam melindungi tanaman terhadap dampak cekaman abiotik. Hasil yang sama juga dilaporkan oleh Wang, et al (2014), bahwa pemberian silika tidak mempengaruhi pertumbuhan tanaman padi, tetapi lebih berperan penting dalam melindungi tanaman teradap cekaman abiotik dan biotik seperti kekeringan, keracunan unsur hara, dan serangan hama dan penyakit. Puteri et al (2014) mengungkapkan pemberian silika sampai dosis $4 \mathrm{~g} / 10 \mathrm{~kg}$ tanah pada tanaman kedelai tidak memberikan pengaruh yang berbeda pada semua variabel pengamatan. Hasil yang berbeda disampaikan oleh 
Subiksa (2018), Pemberian pupuk silika juga meningkatkan ketahanan terhadap rebah karena batangnya lebih kuat dan anakannya lebih banyak.

Tabel 6. Serapan Si Pada Jaringan Tanaman Padi

\begin{tabular}{lcc}
\hline Perlakuan & $\begin{array}{c}\text { Serapan Silikat Pada Jaringan } \\
\text { Tanaman padi }(\mathrm{g})\end{array}$ & $\begin{array}{c}\text { Serapan Silikat Pada Jaringan } \\
\text { Tanaman Padi }(\%)\end{array}$ \\
\hline A1 & $2,67 \mathrm{a}$ & $8,97 \mathrm{a}$ \\
A2 & $2,52 \mathrm{a}$ & $8,75 \mathrm{a}$ \\
A3 & $2,28 \mathrm{a}$ & $9,12 \mathrm{a}$ \\
\hline BNJ & - & - \\
\hline V1 & $2,65 \mathrm{a}$ & $8,69 \mathrm{a}$ \\
V2 & $2,39 \mathrm{a}$ & $9,24 \mathrm{a}$ \\
\hline BNJ & - & - \\
\hline A1V1 & $2,83 \mathrm{a}$ & $8,50 \mathrm{a}$ \\
A1V2 & $2,48 \mathrm{a}$ & $8,60 \mathrm{a}$ \\
A2V1 & $2,68 \mathrm{a}$ & $8,73 \mathrm{a}$ \\
A2V2 & $2,34 \mathrm{a}$ & $8,77 \mathrm{a}$ \\
A3V1 & $2,47 \mathrm{a}$ & $7,97 \mathrm{a}$ \\
A3V2 & $2,133 \mathrm{a}$ & $10,37 \mathrm{a}$ \\
\hline BNJ & - & -
\end{tabular}

Keterangan: Angka-angka yang diikuti dengan huruf yang sama pada kolom yang sama menunjukkan tidak berbeda nyata pada uji lanjut BNJ dengan taraf nyata 5\%

Sumber: Data Primer diolah (2020)

\section{KESIMPULAN DAN SARAN}

\section{Kesimpulan}

Berdasarkan hasil analisis dan pembahasan yang dilakukan, maka dapat ditarik beberapa kesimpulan sebagai berikut:

1. BV tertinggi ditunjukkan oleh abu sampah kota, $\mathrm{pH}$ tertinggi ditunjukkan oleh abu sampah kota, C-Organik tertinggi ditunjukkan oleh abu sampah kota, N Total tertinggi ditunjukkan oleh abu sekam padi, dan $\mathrm{C}-\mathrm{N}$ rasiotertinggi ditunjukkan oleh abu sampah kota.

2. Perlakuan abu (abu sekam padi, kuit kacang tanah, dan abu sampah kota) (A) dan kombinasi abu (A) dan varietas (V) tidak berpengaruh nyata terhadap semua parameter yang diamati

3. Perlakuan varietas Inpari 32 (V1) berpengaruh nyata terhadap berat berangkasan basahdan berat berangkasan kering. Seain itu varietas Inpari 32 lebih responsif; danvarietas Inpari 32 ini lebih superior dibandingkan dengan varietas Ciherang.

4. Perakuan abu sampahkota (A3) dan interaksi abu sampa kota dan varietas Ciherang (A3V2) menunjukkan serapan Siika tertinggi jika dibandingkan abu yang lain.

\section{Saran}

Perlu dilakukan kajian ulang menggunakan varietas padi dan tanaman gramineae yang berbeda. 


\section{DAFTAR PUSTAKA}

Badan Penelitian Tanah. 2011. Silika Sebagai Unsur Hara [Online]. www.pustakalitbang. deptan.go.id. (Diakses: 16 Oktober 2017)

Juliardi, I., Gani, A. (2002). Pemberian Bahan Organik dan Pupuk P Pada Padi Sawah. Pusat Penelitian dan Pengembangan Pertanian: Bogor.

Meyovy, K. 2011. Pengertian Pupuk dan Pemupukan [Online]. http//meyovy's blogspot.com/2011//11/pengertianpupukdanpemupukan.html. (Diakses: 27 Juni 2016).

Poedjiadi, A. (1994). Dasar-Dasar Biokimia. Jakarta: Universitas Indonesia.

Puteri, E. A., Nurmiaty, Y., \& Agustiansyah. (2014). Pengaruh Aplikasi Fosfor Dan Silika Terhadap Pertumbuhan Dan Hasil Tanaman Kedelai (Glycine max [L.] Merrill.). Jurnal Agrotek Tropika, 2(2), 241-245. https://doi.org/10.23960/JAT.V2I2.2092

Septiadi, D., \& Joka, U. (2019). Analisis Respon dan Faktor-Faktor yang Mempengaruhi Permintaan Beras Indonesia. AGRIMOR, 4(3), 42-44.

Septiadi, D., Harianto, H., \& Suharno, S. (2016). Dampak Kebijakan Harga Beras dan Luas Areal Irigasi Terhadap Pengentasan Kemiskinan di Indonesia. Jurnal Agribisnis Indonesia (Journal of Indonesian Agribusiness), 4(2), 91-106.

Subiksa, I. G. M. (2020). Pengaruh Pupuk Silika terhadap Pertumbuhan dan Hasil Tanaman Padi Sawah pada Inceptisols. Jurnal Tanah Dan Iklim, 42(2), 153-160. https://doi.org/10.21082/jti.v42n2.2018.153-160

Wang, W., Yu, Z., Zhang, W., Shao, Q., Zhang, Y., Kuo, Y., Jiao, X., \& Xu, J. (2014). Respones of rice yield. Irrigation water requierement and water use efficiency to climate change in China: Historica simulation and future projections. Aric.Water Manag. 249-261.

Yukamgo. (2007). Peranan Silikon. Jurnal Ilmu Tanah dan Lingkungan, 7(2). 